Induction arrangements have improved in the study period. Similarly, comprehensive arrangements occur on the majority of sites where ECT is given. The Royal

original papers

College of Psychiatrists is now inspecting ECT facilities and training and accrediting clinics. It remains a matter of concern that on seven (27\%) sites supervision is unsatisfactory. Feedback received at deanery visits indicates that this is often because the consultant responsible for the service is timetabled to be off site when treatment is being given. Phlebotomy services are often poor on isolated community sites away from the general hospital. We know from feedback that many NHS trusts are addressing this issue by training nurses to assist in this task.

The Department of Health document, A Health Service of all the Talents (Department of Health, 2000), has emphasised the importance of multi-professional training in the service setting. Unfortunately, the majority of trainees in this study had little access to meetings in which they could share knowledge and discuss and debate issues with other health professionals. However, this may be partially explained by the fact that doctors have traditionally enjoyed easier access to protected study leave time and money than other professional groups. However, there are also doubts raised about the value of multi-professional learning. Frankly, there is a dearth of studies assessing multi-professional training in secondary care. However, in primary care Mann et al (1996) have shown benefits in collaborative working by delivering a multi-professional heart health programme to doctors and other health and social care professionals, and in undergraduate courses similar benefits have been described (Wahlstrom et al, 1997; Parsell et al, 1998). For a review of this topic see Herzberg (1999). Psychiatrists face a significant challenge to ensure that trainees have access to educational programmes that promote learning of core skills, attitudes and knowledge necessary for practice in the speciality, but also promote shared learning with other clinical health professionals.

This study demonstrates that psychiatric training had improved over a 3-year period in one deanery, but there will need to be a considerable amount of work undertaken to meet the challenges of the new NHS training agenda.

\section{References}

DEPARTMENT OF HEALTH (2000) A Health Service of all the Talents: Developing the NHS Workforce. London: Department of Health.

HERZBERG, J. (1999) Tribes or teams? The challenge of multiprofessional education. Hospital Medicine, 60, 516-518.

-, FERGUS, K., PAICE, E. (1999)

Regional review of psychiatric training. Psychiatric Bulletin, 23, 675-677.

MANN, K.V., VISCOUNT, P.W., COGDON, A., et al (1996)

Multidisciplinary learning in continuous professional education: the Heart Health Nova Scotia Experience. The Journal of Continuing Education in the Health Professionals, 16, 50-60.

PAICE, E., WEST, G., COOPER, R., et al (1997) Senior house officer training: is it getting better? BMJ, 314, 719-207.

- AITKEN, M., COWAN, G., et al (2000) Trainee satisfaction before and after the Calman reforms of specialist training: questionnaire survey. $B M J$, $320,832-836$

PARSELL, G. SPALDING, R. \& BLIGH, J. (1998) Shared goals, shared learning; evaluation of a multi-professional course for undergraduate students. Medical Education, 32, 304-311.

ROYAL COLLEGE OF PSYCHIATRISTS (1998) Higher Specialist Training Handbook. Occasional Paper OP43. London: Royal College of Psychiatrists.

- (1999) Basic Specialist Training Handbook. London: Royal College of Psychiatrists. http// www.respsych.ac.uk/traindev/ postgrad/bst.pdf

WAHLSTROM, O., SANDEN, I. \& HAMMAR, M. (1997) Multiprofessional education in the medical curriculum. Medical Education, 31, 425-429.

*Joe Herzberg Associate Dean of Postgraduate Medicine (north-east London) Elisabeth Paice Dean Director, Thames Postgraduate Medical and Dental Education (now London Department of Postgraduate Medical and Dental Education), 20 Guilford Street, LondonWC1N 1DZ

\title{
Mental health presentations to an inner-city accident and emergency department
}

\author{
AIMS AND METHOD \\ To study the presentation, assess- \\ ment and management of \\ all patients attending St Thomas' \\ accident and emergency (A\&E) \\ department with overt mental \\ health problems. The method \\ included a pragmatic definition \\ of 'overt mental health problems' \\ and a range of strategies to \\ maximise case ascertainment.
}

\author{
RESULTS \\ The department saw 565 presenta- \\ tions in a 3-month period. Patients \\ were predominantly young, male, \\ single, unemployed, housed outside \\ the area served by the local primary \\ care group and presented outside \\ normal working hours.
}

\author{
CLINICAL IMPLICATIONS \\ This study confirms that A\&E \\ departments may be the most \\ frequently used setting for urgent \\ mental health assessments in central \\ London. The patients attending \\ differ from those using community \\ mental health teams. It is argued that \\ mental health liaison services based \\ in inner-city $A \& E$ departments should \\ be developed.
}

Accident and emergency (A\&E) departments are the most frequently used facility for urgent mental health assessments both within and outside office hours

(Johnson \& Thornicroft, 1995). This finding holds even 
where well-established community mental health teams (CMHTs) are available locally (Crawford \& Kohen, 1997). Yet the recent King's Fund Report, London's Mental Health (Johnson et al, 1997), made no reference to the role of A\&E departments in service provision. The National Service Framework for Mental Health (Department of Health, 1999) demands 24-hour access to mental health services and acknowledges that A\&E departments have a role in this, but downplays their centrality to current patterns of mental health care in London. Psychiatric practice in the A\&E department has been unpopular with patients, carers and professionals and has remained underresearched. We studied activity in one A\&E department as a baseline for service development and further research.

\section{Method}

We undertook a prospective descriptive study of the presentation, assessment and management of all patients with overt mental health problems attending the A\&E department at St Thomas' Hospital, London, over a 3-month period. Overt mental health problems included psychiatric morbidity noted by a health professional as the main cause for presentation, or a patient request for psychiatric help or deliberate self-harm (DSH) presentations. The latter were included because they require a psychosocial assessment. Overt psychiatric presentations were ascertained by hand searching clinical notes daily, liaising with mental health professionals active in the department and searching the A\&E departmental computer. A form was completed by S.C. for each patient. This covered socio-demographic data, presenting problems, past psychiatric history (including service contact) and information on pathways of care in the $A \& E$ department.

\section{Results}

There were 565 attendances with overt psychiatric problems in the period October to December 1997. The patients were predominantly young (mean age 33), male (64\%), single (56\%) and unemployed (53\%). Only $43 \%$ had home addresses within the area served by the local health authority (now primary care group), with $17 \%$ of patients describing themselves as of no fixed abode. The most frequent presenting problems were DSH (31\%), substance misuse (mostly alcohol) (20\%), psychosis (17\%) and mood disturbance (15\%). Fifty-eight per cent of patients declared a past history of mental health problems, with DSH, depressive illness and schizophrenia being the most common. Over a third of patients were in contact with mental health services elsewhere at the time of A\&E attendance.

Seventy per cent of these presentations were outside the office hours of 9 a.m. to 5 p.m., Monday to Friday. Four per cent of patients left unassessed and $82 \%$ were assessed by a mental health professional in A\&E. Thirty per cent of presentations resulted in hospital admission $-20 \%$ to psychiatric units and $10 \%$ to general wards (typically with self-harm or delirium tremens). Further care for the other patients included general practitioner (GP) follow-up (15\%), no follow-up (12\%) and referral to CMHTs (14\%), drug and alcohol services (9\%) and social workers $(0.5 \%)$.

\section{Comment}

A\&E departments in inner-cities play an important role in the management of mental health problems. They especially serve young men who are single, unemployed and often homeless, who present outside office hours and among whom there is an epidemic of completed suicide (Hawton \& Fagg, 1992). The prevailing ideology has been that enhanced community mental health services will reduce presentations to A\&E departments. However, it is clear that community teams serve a very different population to A\&E departments, being specifically aimed at those with severe, enduring mental illness and permanent residence in a catchment area.

The department studied here had the benefit of two mental health nurses based in A\&E and continuous junior and senior psychiatric cover. This probably explains the relatively high percentage of specialist mental health assessments undertaken in the St Thomas' A\&E department compared with those reported in other $A \& E$ departments for all psychiatric presentations (52\%) (Dunn \& Fernando, 1989) and DSH in particular (54\%) (Kapur et al, 1998).

Psychiatric presentations to A\&E departments serving deprived urban areas are unlikely to diminish in number and dedicated mental health services are urgently required to meet these needs. The strict sectorisation of community mental health services poses a funding problem for mental health work in A\&E departments. Funding arrangements for patients coming to A\&E who live outside the local area need to be resolved. The advent of primary-care-led mental health service commissioning threatens to sideline the role of the general hospital in mental health provision for non-local patients even further.

The National Service Framework for Mental Health (Department of Health, 1999) does acknowledge that A\&E departments can make a valuable contribution to 24-hour access to services, particularly for patients who have deliberately self-harmed, 'rough sleepers' and those not registered with a GP. However, the underlying assumption guiding national policy seems to be that A\&E departments are not the right environment for mental health assessments out of hours. Telephone helplines, extended hours for CMHTs and domiciliary visits by GPs are often mentioned as alternatives. We would argue that spending on these developments is unlikely to divert patients with mental health problems from A\&E departments. Investment in dedicated A\&E mental health liaison services could transform the quality of patients' and professionals' experiences of A\&E psychiatry and lead to the view that this is a preferred point of access to mental health services, especially out of hours. 
Since these data were collected, the local health authority, mental health trust and acute hospital trust have collaborated to expand the A\&E mental health

original papers liaison team at St Thomas' Hospital as the A\&E department merged with that formerly at Guy's. The team now includes a dedicated consultant psychiatrist, a staff grade psychiatrist and eight psychiatric liaison nurses (including a team leader) in addition to rotas of consultants and trainee psychiatrists both in and out of hours. The nurses aim to provide cover 24-hours a day. We hope to publish descriptions of the practice of this enlarged A\&E mental health liaison team as it may prove to be a model for other large, inner-city A\&E departments.

\section{Acknowledgements}

We thank Bob Taylor and Mark Roberts of the A\&E department at St Thomas' and Sarah Ireland of Lambeth Healthcare NHS Trust for their assistance with data collection. At the time of this study S.C. was funded by the Priory Hospitals Group.

\section{References}

CRAWFORD, M. J. \& KOHEN, D. (1997) Urgent psychiatric assessment in an inner-cityA\&E department. Psychiatric Bulletin, 21, 625-626.

JOHNSON, S. \& THORNICROFT, G. 1995) Emergency psychiatric services in England and Wales. BMJ, 311, 287-288

DEPARTMENT OF HEALTH (1999)

National Service Framework for Mental Health: Modern Standards and Service Models. London: Department of Health.

- RAMSAY, R., THORNICROFT, G., et al (1997) (eds) London's Mental Health The Report to the King's Fund London Commission, 1997. London: King's Fund.

DUNN, J. \& FERNANDO, R. (1989) Psychiatric presentations to an accident and emergency department. Psychiatric Bulletin, 13, 672-674.

HAWTON, K. \& FAGG, J. (1992) Trends in deliberate self poisoning and self injury in Oxford, 1976-90. BMJ, 304, 1409-1411.

KAPUR, N., HOUSE, A., CREED, F., et al (1998) Management of deliberate self poisoning in adults in four teaching hospitals: a descriptive study. BMJ, 316, 831-832.

S. Cassar Priory Research Fellow, *A. Hodgkiss Honorary Senior Lecturer, A. Ramirez Professor, Department of Liaison Psychiatry, Guy's, King's \& StThomas' Medical \& Dental School, StThomas' Hospital, London SE1 7EH, D. Williams Consultant, Department of Accident \& Emergency Medicine, Guy's \& StThomas' HospitalsTrust 